\title{
Exploration of Intellectual Property Protection Strategies for Cross-border E-commerce
}

\author{
Dr. ChunYi Lin ${ }^{1}$ \\ ${ }^{1}$ School of Economic and Management, Nanning Normal University, Nanning, Guangxi
}

\begin{abstract}
The continued advancement of the "One Belt, One Road" strategy, coupling with the rapid development of the Internet, has provided a convenient online platform for cross-border e-commerce enterprises. China's cross-border e-commerce enterprises have made unprecedented progress. However, at the same time, the problem of intellectual property infringement in cross-border e-commerce has become increasingly prominent, seriously restricting the development of China's cross-border e-commerce enterprises. On the basis of analyzing the intellectual property strategy of enterprises.

This paper describes the necessity of creating an intellectual property strategy for cross-border e-commerce enterprises, and proposes strategies for building relevant intellectual property strategies aimed at the weak awareness of intellectual property and the copycatting of enterprise products, which are common in the operation of cross-border e-commerce enterprises in China.
\end{abstract}

\section{INTRODUCTION}

According to the survey of the China E-commerce Report 2019 released on June 30, 2020.In 2019, China's total ecommerce transactions reached 34.81 trillion yuan, of which online retail sales were 10.63 trillion yuan, up $16.5 \%$ year-on-year, and online retail sales of physical goods were 8.52 trillion yuan, accounting for $20.7 \%$ of the total retail sales of consumer goods. Combined with the 618 war reports and sales lists of Jingdong, Taobao and Sunning can be seen that in the current digital economy. The digital economy has become a key part of China's economic growth in $\mathrm{China}^{[1]}$. Cross-border ecommerce is a foreign development strategy in ecommerce transactions, according to Ali's data estimates.China's cross-border e-commerce transactions in 2020 can reach 12 trillion yuan, accounting for $37.6 \%$ of China's total import and export, coupled with the upgrading and development of cross-border e-commerce platforms, cross-border e-commerce industry is bound to continue to grow rapidly.At the same time, cross-border e-commerce in intellectual property issues will also become the market industry in the development of the hurdle to create an intellectual property strategy for crossborder e-commerce enterprises has far-reaching significance and impact on promoting the development of cross-border e-commerce enterprises.Based on that we should do more research to find the best intellectual property strategy for the oversea SME e-commerce corporation.

\section{CONNOTATION, ROLE AND CHARACTERISTICS OF CORPORATE INTELLECTUAL PROPERTY STRATEGY}

\subsection{Context of corporate IP strategy}

Intellectual property rights are the exclusive rights on the fruits of intellectual work created by human beings in social practice. Enterprise intellectual property strategy refers to the enterprise to obtain and maintain a competitive advantage in the market.The use of intellectual property rights system to ensure that the protection and use of intellectual property rights to seek the best economic benefits of the strategy and means. Depending on the different rights holders, intellectual property strategy can be divided into national, industrial and enterprise intellectual property strategy. Intellectual property strategy can usually be understood as the application of the intellectual property system under the relevant institutional norms, and it can be said that intellectual property strategy is the specific implementation measures of the intellectual property system ${ }^{[2]}$.

\subsection{The role of corporate intellectual property strategy}

In modern society, corporate intellectual property strategy is of great help to enterprise development. Firstly, it can realize the overall improvement of the enterprise's core

lukelin@nnnu.edu.cn 
competitiveness and innovation ability. Secondly, it can conduct a more thorough study of the intellectual property system to ensure that the intellectual property system can be better and more effectively implemented.And in addition, intellectual property strategy can also be used as a defensive means to prevent the infringement of the enterprise's own intellectual property ${ }^{[3]}$. Finally, corporate intellectual property strategy can enhance corporate innovation and influence and ensure the sustainable development of enterprises through intellectual property transactions

\subsection{Characteristics of Intellectual Property Strategy}

Legally, corporate intellectual property strategy is implemented on the basis of intellectual property laws. On the one hand, intellectual property laws can constrain the corporate intellectual property strategy and ensure the normative behavior of the corporate intellectual property strategy.And on the other hand, intellectual property laws can also guarantee the implementation of the corporate intellectual property strategy ${ }^{[4]}$. In general, the use and development of corporate intellectual property resources cannot be separated from the joint role of intellectual property laws and corporate intellectual property strategies.

Confidentiality, corporate intellectual property strategy is an integral part of the enterprise development strategy. In the business activities of enterprises, including intelligence analysis, market forecasts, product development and business direction. Once the competitors know, it can be a fatal blow to the development of enterprises. That is why the implementation of the corporate intellectual property strategy needs to be confidential with regard to the contents of the commercial secret field.

For temporarily, in the case of the expiration or cessation of the corporate intellectual property limit, the corporate intellectual property strategy should also be adjusted accordingly. For territoriality, the formulation and implementation of the corporate IP strategy should be carried out in conjunction with the place where the IP rights are generated, so as to match the business activities of the enterprise.

Non-independence, which is reflected in the coordination with the implementation of corporate strategy. In general, the implementation of corporate intellectual property strategy needs to match with other strategies of the enterprise, and it is difficult to achieve the expected purpose by using corporate intellectual property strategy alone ${ }^{[5]}$.

\section{THE NECESSITY OF CREATING A CROSS- BORDER E-COMMERCE ENTERPRISE IP STRATEGY}

\subsection{Implementation in line with national IP strategies}

On June 5, 2008, China issued the Outline of the National Intellectual Property Strategy (hereinafter referred to as the Outline), which stressed that in order to improve our ability to create, apply, protect and manage intellectual property rights, and with the Deng Xiaoping Theory and the "Three Represents" important thought as a guide, we need to focus on improving the intellectual property rights system, actively create A good intellectual property rule of law environment, market environment, cultural environment, greatly improve China's intellectual property creation, application, protection and management capabilities, to build an innovative country and build a moderately prosperous society in an all-round way to provide strong support.The goal is to build China into a country with a higher level of intellectual property creation, application, protection and management by 2020 In order to achieve this strategic goal, we need the cooperation of the enterprise intellectual property strategy, enterprises as the main body of market economic activities.The creation and implementation of its intellectual property strategy effect is of great significance to the realization of the national intellectual property strategy ${ }^{[6]}$

\subsection{Implementation in line with the innovation- driven development strategy}

The 18th National Congress of the Communist Party of China (CPC) clearly stated that "scientific and technological innovation is a strategic support for improving social productivity and comprehensive national strength, and it must be placed at the core of the overall national development situation." Premier Li Keqiang said on July 11 that efforts should be made to build a strong country with intellectual property rights ${ }^{[7]}$. At present, intellectual property has become a strategic resource and core element of economic development, and realizing a strong IPR nation is an inevitable choice for implementing the innovation-driven development strategy. To build an innovative country, we should focus on five aspects, including intellectual property system, intellectual property industry, intellectual property environment, intellectual property personnel and intellectual property culture, and use a sound intellectual property system to protect the intellectual property of enterprises to form a virtuous cycle.

\subsection{In line with the implementation of the "Belt and Road" strategy}

China released the "Vision and Action of Belt and Road" on March 28, 2015, which emphasizes the innovation of trade methods and the development of cross-border e- 
commerce and other new business models. The construction of China's "One Belt, One Road" strategy needs the escort of intellectual property rights.According to the relevant survey, $85 \%$ of Chinese enterprises occupy the patent application enterprises submitted by the "One Belt, One Road" countries. "The level of science and technology in the countries along the Belt and Road ${ }^{[8]}$. On the other hand, in the case of patent infringement, it will adversely affect the international development of Chinese enterprises.

\section{ANALYSIS OF THE CURRENT INTELLECTUAL PROPERTY STATUS OF CHINA'S CROSS- BORDER E-COMMERCE ENTERPRISES}

With the deep influence of the global economy, consumer demand has gradually tilted towards small-value trade, coupled with the rapid improvement of Internet technology.The cross-border e-commerce industry has continued to rise, and small cross-border e-commerce has developed particularly rapidly. In this environment Most of China's small and medium foreign trade enterprises participate in international trade by means of cross-border e-commerce.In order to realize the development of international trade, but at the same time, the issue of corporate intellectual property rights has also followed. Because cross-border e-commerce is an emerging business, and most cross-border e-commerce companies are small and medium-sized enterprises. These companies know little about the importance of intellectual property protection, so they are easily attacked by intellectual property rights on e-commerce platforms. The most common is the phenomenon of "cottage". The products sold by the company belong to independent research and development brands. In the process of selling. They are most likely to follow the trend and be copied. These "used" sellers do not understand that the products they sell are protected by intellectual property rights. In general, they are in trouble directly after receiving complaints and are forced to remove products or close stores, which has a huge impact on the development of e-commerce business [9].

\subsection{The fingertip gyro case}

Take the fingertip gyro as an example. The sales volume of the fingertip gyro in European countries is very hot, and it once occupied the top of the e-commerce sales list. This product was registered by Angel Company on March 9,2017 , and the patent took effect on the same day. Some small and medium-sized cross-border in China Ecommerce companies don't understand this information and only care about their sales volume. During the sales process, due to patent infringement issues, the PayPal accounts of thousands of Chinese sellers were frozen and countless e-commerce platforms went bankrupt.

\subsection{From "Legend" to" Lenovo"}

Some companies have a certain sense of intellectual property rights and have trademarks for this product. However, due to lack of preliminary planning.Before applying for product trademarks overseas, they found that their product trademarks have been applied for and entered the announcement period. In such cases of squatting, they need to takes more time and money to fight for trademarks, which seriously affects its own product sales. Take Lenovo as an example. In the process of global development in 2001, Lenovo found that Lenovo's English name "Legend" was over Many companies registered and involved various fields. Lenovo wanted to grab this trademark, but found that it needed to talk to more than 100 companies. In desperation, it changed "Legend" to "Lenovo".

\section{Intellectual Property Improvement StRategy Path of Chinese Cross-Border E-COMMERCE ENTERPRISES}

\subsection{Create a strategic protection mechanism for corporate intellectual property rights}

The formulation of an enterprise's intellectual property strategy is a complicated and delicate process. First of all, it is necessary to clarify the positioning and development direction of cross-border e-commerce enterprises. The formulation of intellectual property strategies for an enterprise at different stages of development is also different. For example, enterprises in the development stage shall give priority to establishing commercial confidentiality measures. For enterprises in the stable development stage, Prioritize layout with trademarks and other intellectual property rights in order to seek more profits. Secondly, sort out the status quo of the company's intellectual property rights, understand which intellectual property rights the company has, and what its value and protection status are. On this basis, combining the different needs of intellectual property rights, we will formulate targeted intellectual property strategies that meet the needs of the company. Finally, according to the actual market competition of the enterprise, the enterprise intellectual property strategy is formulated.Under normal circumstances, the intellectual property strategy can be formulated by professional institutions and enterprises. Its manifestation is in the form of documents. It should be noted that different types of intellectual property rights. The formulation and application process of the company is different. It is necessary to understand the relevant national policies and enterprise development plans in advance to make a reasonable layout. Take the trademark registration process as an example,the general process is trademark search, application documents, application submission, trademark examination, substantive examination, trademark announcement, certificate issuance, etc. The total duration is 13 months. Therefore, companies need to sell their products according to the time of sale., Adjust the trademark registration time in 
time to ensure the smooth achievement of the company's current goals ${ }^{[11]}$.

\subsection{Optimizing domestic and overseas intellectual property management systems}

Only by relying on the intellectual property management system can the intellectual property strategy be effectively constructed and implemented. Under the regulation of the intellectual property system, the intellectual property strategy can play its overall role. For enterprise product trademarks and patents and other intellectual property rights, it is necessary to implement the institutionalization of management in response to geographical expansion and the gap in overseas markets. On the basis of strengthening the technical contract management mechanism, the intellectual property file management system should be adjusted and based on this series of auxiliary management systems such as the intellectual property reward and punishment system and the intellectual property confidentiality system ${ }^{[12]}$. The establishment of the system is strictly carried out in accordance with the business progress and development direction of the enterprise. Once the system is determined, it needs to be implemented carefully to ensure the normalization and standardization of the enterprise's intellectual property management work. In addition, the evaluation of the implementation of the enterprise's intellectual property system is also very important. The implementation determines the effect of the implementation and affects the final implementation of the enterprise's intellectual property management strategy. After the evaluation finds problems, timely rectification is carried out to ensure that the enterprise's intellectual property management system can always It conforms to the overall situation of the enterprise, and plays the role of regulation, restriction and incentive of the system.

\subsection{Establish a (virtual) department with international intellectual property expertise}

In response to China's current cross-border e-commerce companies' small scale and weak intellectual property awareness, it is necessary to establish an enterprise intellectual property management department with overseas intellectual property expertise. If the enterprise is small, it will be built with overseas knowledge through professional outsourcing project billing. Ningli's virtual department for property rights management can not only strengthen cross-border e-commerce companies' understanding of intellectual property rights, protect their own products from infringement, and prevent malicious attacks. On the positive side, they can also target different cross-border e-commerce companies. The business enterprise's own positioning and development direction, to find out the potential threats such as unintentional infringement or malicious infringement overseas, to ensure that their products are not infringing, and to prevent the occurrence of claims ${ }^{[13]}$. In addition, it should be noted that the non-independence of corporate intellectual property strategy determines that the corporate intellectual property management department cannot rely on independent operation to generate benefits. Under the circumstance of clarifying the responsibilities of the department and organization, it needs to handle the division of labor and cooperation with other strategic departments. To achieve smooth communication of information resources, so as to ensure that the expected corporate intellectual property strategic goals are achieved.

\section{Conclusion}

With the implementation and continuous advancement of the "One Belt, One Road" strategy, the development of cross-border e-commerce in China will continue to accelerate. In view of the current intellectual property issues of cross-border e-commerce enterprises in China. The companies need to realize the importance of intellectual property management and protection and combined with corporate positioning and development goals, formulate a reasonable and scientific intellectual property strategy, continuously improve the innovation of corporate products, seize market opportunities in the field of cross-border e-commerce, and achieve better and faster development of the company.

\section{REFERENCES}

1. Han Xu. The construction and implementation of the intellectual property strategy of cross-border ecommerce enterprises. Journal of Changchun Normal University (Humanities and Social Sciences Edition),vol.38,pp.67-70, Jan.2019.

2. Zhao Binyuan. Research on the Development of China's Cross-border E-commerce and Government Supervision: Taking Small Cross-border Online Shopping as an Example. Reform and Strategy, vol.033,pp.133-135,Feb. 2017

3. Wu Min. Analysis on the construction of a crossborder e-commerce ecosystem from the perspective of "Internet +". Business Economics Research, vol. 34, pp. 75-76, April. 2015.

4. Chu Xueli. Exploration of financial interconnection to support the development of cross-border ecommerce for small and medium-sized enterprises- Based on the economic development of my country and the countries and regions along the Belt and Road. China Circulation Economy, vol.30, pp.66-74. Jun. 2016.

5. $\mathrm{Hu}$ Wei, Ma Xiao. The Dilemma and Solution of Cross-border E-commerce Intellectual Property Governance[J]. Business Economics Research,, vol.764, pp.143-146, Jan.2019.

6. Li Xinliang. Analysis on the legal protection of intellectual property rights of cross-border ecommerce agricultural products $[\mathrm{J}]$. Business Economics Research, vol:758,pp.130-132, Sep. 2018.

7. Jiang Lixiang. The development model, obstacles and development trend of cross-border e-commerce 
in my country. Price Monthly, vol.6, pp.59-62, Jun.2016.

8. Wang Li, Feng Ying. Research on my country's Intellectual Property Export Policy under the Background of "One Belt One Road". Science and Technology Management Research, vol.039,pp.4448.Sep.2019.

9. Yu Xiaoyan, Zhu Liping. New developments and new problems of China's cross-border e-commerce exports under the new situation_-Based on WTO multilateral trade rules[J]. Foreign Economic Relations and Trade Practice,vol. 006,pp.4144,Jun.2017.

10. Yang Qing. Warning and response to my country's small and medium-sized cross-border e-commerce by the United States intending to withdraw from the
Universal Postal Union. Foreign Economic Relations and Trade Practice, vol.003,pp. 24-27,Mar.2019.

11. Yang Yang, Tao Sijia, Du Jian. The impact of U.S. e-commerce taxation on cross-border Internet companies and its response[J]. Friends of Accounting, vol.2, pp.49-53,Feb.2020.

12. Gao Xiang, Jia Liangting. Research on enterprise cross-border e-commerce supply chain risk based on structural equation model-Taking 167 crossborder e-commerce companies in Shanghai, Guangzhou, Qingdao and other places as examples. Shanghai Economic Research,vol.5, pp.76-83, Jan.2016

13. Zhang Man. Enlightenment of China's Intellectual Property Research from 1978 to 2018. Forum on Science and Technology in China, , Vol:003, pp.107116,Mar.2019. 